\title{
"La ciencia tiene que conformarse con el mundo, pero la ética debe decir que el mundo tiene que cambiar". \\ Entrevista con Michael Barber
}

Carlos Molina y Luis Alvarenga

Departamento de Filosofía UCA, San Salvador

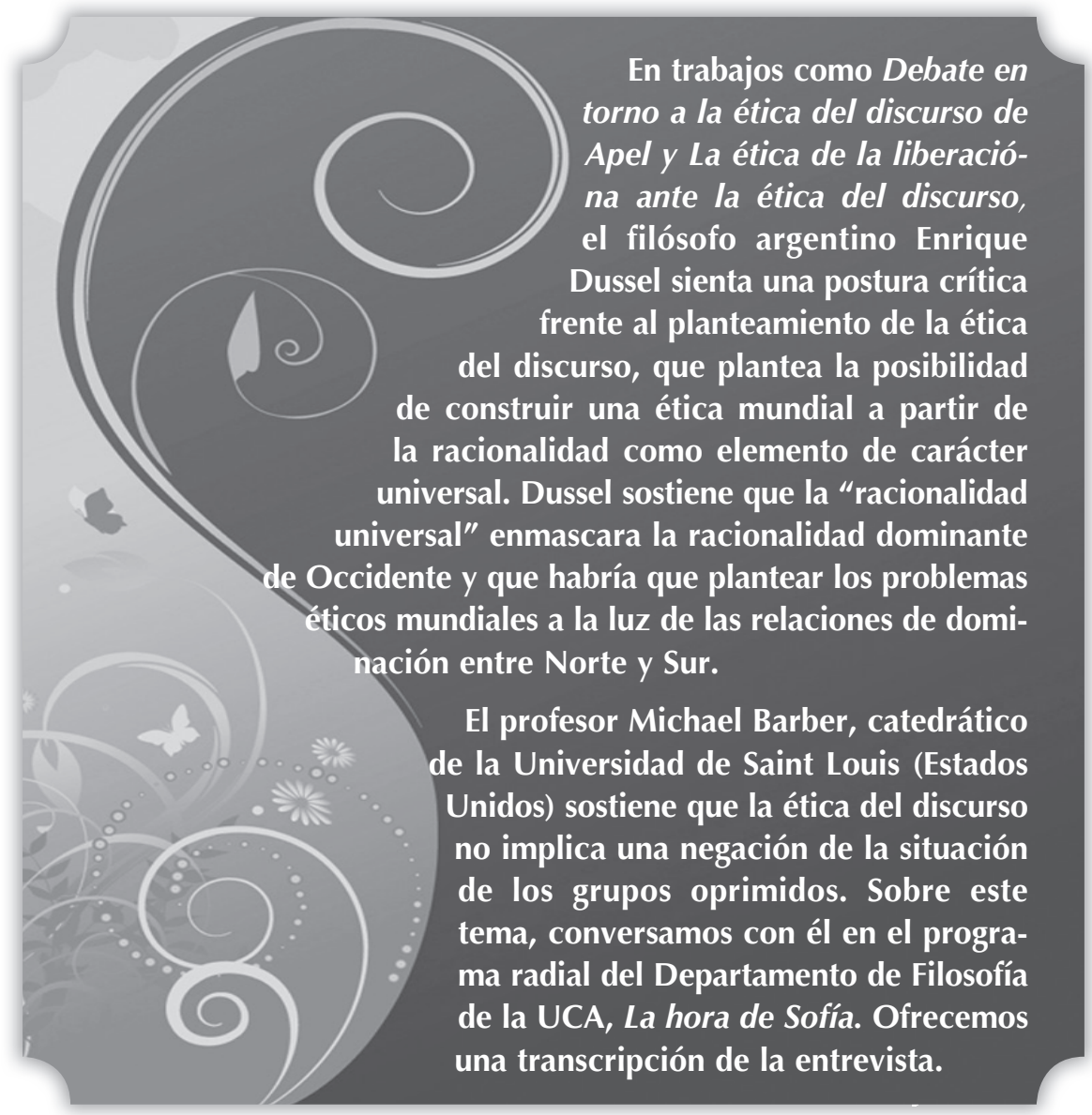


Barber, quien estuvo en el país el año pasado para ofrecer un curso doctoral titulado "Ética y política de la liberación: Lévinas y Dussel", obtuvo su doctorado en la universidad de Yale con una disertación acerca de la sociología del conocimiento de Alfred Schutz. Sobre el tema que compete a esta entrevista, publicó, en 1998, un libro titulado Ethical Hermeneutics: Rationality in Enrique Dussel's Philosophy of Liberation. La Universidad de Ohio le publicará este año el trabajo que lleva por título The Intentional Spectrum and Intersubjectivity: Phenomenology and the Pittsburgh Neo-Hegelians.

\section{Carlos Molina:}

¿Cuáles considera usted que son los problemas filosóficos que se enfrentan quienes intentan formular lo que debería ser una ética mundial?

\section{Michael Barber:}

Yo pienso que muchas de las cosas que están escritas son cosas que debemos pensar, por ejemplo hay que pensar en la mayoría de la humanidad que está sufriendo de hambre, por ejemplo. Por eso yo estoy completamente de acuerdo con las conclusiones a las cuales llega Dussel. Pero también tengo unos problemas con la filosofía de Dussel y de cómo él llega a sus conclusiones. Cuando Dussel se refiere al sufrimiento de la mayoría de la humanidad, yo creo que hay una lucha por mantener la racionalidad, que puede criticar lo que no es bueno, y a la vez hacer una crítica de la racionalidad misma que no puede ser suficientemente amplia, que se puede encerrar en sí misma, que se puede olvidar del sufrimiento del resto de la humanidad.

\section{Carlos Molina:}

Y esa concepción de la racionalidad en sí misma, ¿no debería ser cuestionada? Usted plantea que esta racionalidad puede descuidar ciertas cosas, pero en un filósofo como Dussel, probablemente el problema no sea este y se piense que esto no es suficientemente radical. ¿No será más bien que es esta misma radicalidad, porque también es una racionalidad históricamente constituida la que genera los problemas? ¿Cómo lo ve usted esto?

\section{Michael Barber:}

Yo pienso que la crítica de la racionalidad es una obra de la racionalidad, y que la racionalidad se mejora por eso. También hay que considerar la racionalidad como una cosa normativa. Entonces podemos ver una racionalidad que se encierra en sí misma, y podemos decir que esto no es justo, que no es razón, sino una ideología que está encubriendo la realidad. Pero esta queja es una crítica de la racionalidad a la misma vez: se usa la razón porque estamos viendo que esta racionalidad no es suficientemente 
razonable, está influida por otros deseos y otros intereses que están distorsionando la racionalidad. Yo acudo muchas veces al planteamiento de Emmanuel Lévinas, que habla de una relación ética con la otra persona, que es la conclusión de la racionalidad. Cuando yo tengo un encuentro con otra persona, en ese momento yo me siento como desafiado por la otra persona, y en ese contexto surge la racionalidad porque yo tengo la responsabilidad de responder a la otra persona, y también si otra persona está sufriendo, éste pone preguntas a mi forma de ser racional o lo que yo pienso. A mí me gusta eso como un desafío constate de la racionalidad, que es la responsabilidad que yo tengo con lo otro y a la otra persona éticamente.

\section{Luis Alvarenga:}

Usted decía que concuerda mucho con las conclusiones de Dussel, pero no tanto con el camino por el que llega a estas conclusiones. ¿Por qué?

\section{Michael Barber:}

A mí me gusta Lévinas en este sentido, pero yo pienso que es necesario establecer dos niveles: este nivel del encuentro con la otra persona, que es como el comienzo de la racionalidad y que es un desafío a la racionalidad, pero el problema que yo tengo con Dussel es con su formalismo. Yo pienso que esta es una mala interpretación de lo que dicen Apel y Habermas especialmente. El formalismo, según Dussel, es que yo tengo que huir de los problemas, de las cosas materiales, del hambre, de las personas, y yo pienso que esto no es exactamente lo que estos autores están haciendo. Habermas, por ejemplo, dice que en una discusión sobre la ética necesitamos que las personas traigan sus problemas, problemas que tienen que ver con la materialidad, con el hambre, y éste es el comienzo sobre el cual debemos reflexionar. En éste momento comenzamos con un proceso de justificación filosófica: si yo veo que el hambre es horrible, que hay injusticias en el mundo, tengo que desarrollar una justificación por la cual puedo decir que esto no es éticamente correcto. ¿Cómo voy hacer eso? Yo pienso que en Habermas y Apel hay elementos importantes en este sentido. Primero tenemos que pensar en nuestro modo de reflexionar: estamos haciendo ética y no ciencias naturales por ejemplo. En las ciencias naturales partimos de los hechos, por ejemplo, un eclipse de luna, pero con la ética necesitamos principios, porque esta es nuestra forma de razonar. Ahora tenemos que decir cuáles son los principios, y después debemos justificar éstos principios. Yo pienso que Apel y Habermas están diciendo entonces, que si nos enfrentamos con problemas como el hambre, la injusticia, la violencia, en el mundo, especialmente estos problemas 
internacionales, debemos buscar un principio.

Aún podemos ver en el mundo diario que esto es una degradación de las personas humanas, y esto no es justo porque es una degradación. Debemos tratar a uno y a otro como un fin en sí mismo, y vivimos en sistemas económicos y políticos que maltratan a las personas, que degradan a las personas, que no tratan a las personas como fines en sí mismos. ¿Cómo voy a justificar este principio? Yo pienso que Apel y Habermas plantean que debemos ofrecer argumentos que permitan la libertad de la otra persona para poder estar de acuerdo, o de estar en desacuerdo con nosotros, entonces en el argumento estamos tratando. Una persona que niegue la validez de la argumentación no puede argumentar en realidad, porque va entrar en una contradicción performativa.

\section{Carlos Molina:}

Yo estaba pensando que Dussel podría responder recurriendo a una crítica que hace Richard Rorty a Habermas y a Apel, en el sentido de que estos dos autores están pensando que esa estructura racional la compartimos todos, y ese compartir, diría Apel, es un compartir trascendental de alguna forma, esa estructura de ser discurso, y esa comunicación que hay entre nosotros sobre éstos problemas que nos atañen a todos, que son problemas distintos pero que la estructura formal, ahí es donde vendría lo de formalismo, la estructura formal es algo que compartimos todos, pero Rorty diría que esta es la trampa, porque esto que usted considera trascendental, etc. realmente no lo es, es algo que en realidad ha sido construido históricamente. Habermas y Apel piensan así no sólo por ser humanos, sino porque son alemanes del siglo veinte, porque son europeos, porque han recibido una historia del desarrollo de la ilustración y de la modernidad europea, y de las ideas liberales, etc. Entonces Dussel podría agarrar este argumento y afirmar que esto tiene una limitación porque es fruto de la modernidad europea. Es decir, si ahora estamos hablando de un proyecto, de una ética mundial incluyente etc., ¿no será esto una limitación?, ¿no será que hay una especie de ilusión al pensar que estos son principios trascendentales? En otras palabras, el formalismo que Dussel mira en Apel y Habermas hace alusión quizás a esa noción de que hay acuerdos o principios trascendentales. ¿Cómo ve usted esto?

\section{Michael Barber:}

Buena pregunta. Yo pienso que si Rorty va a argumentar conmigo exactamente como tú dices, yo le diría: "mire, señor Rorty usted presupone que voy a escucharlo, que no voy a usar violencia para silenciarlo". Yo pienso que esto pasa muchas veces en otras culturas, 
por ejemplo. En esta idea vamos a entrar en niveles más prácticos en vez de este nivel trascendental. Yo pienso que esto pasa mucho en un matrimonio. Si una persona está hablando con su esposa, y no está de acuerdo en la forma que está reaccionando, ella entra en un discurso, pero en un nivel muy práctico, iy qué es lo que espera? Un argumento. No espera violencia, no espera coerción. Ella está esperando que yo como esposo la respete a ella como un fin en sí mismo. Ella tiene derecho a decir lo que quiera, yo tengo que escuchar lo que ella diga, y yo espero lo mismo de ella. Pienso que es lo mismo: en un discurso sobre estos problemas no podemos evitar este presupuesto.

Apel y Habermas reflexionan sobre lo que cualquier persona presupone en cualquier discusión sobre lo que debemos hacer. La ética entra aquí con Lévinas, porque este autor habla de un nivel muy práctico: cuando yo veo a otra persona, siento el Ilamado de esta persona a responderle. Aquí tengo a la otra persona como un fin en sí mismo. Lo que yo quiero hacer es extender la idea de trascendental: yo espero que podamos encontrar esa idea de un ser humano como un fin en sí mismo en niveles muy prácticos, que existen en muchos aspectos de la vida: una persona que viene pidiendo limosnas, por ejemplo. Es esto lo que dice Lévinas y pienso que Apel y Habermas pueden decir lo mismo.

\section{Luis Alvarenga:}

Dussel arguye es que en la relación entre el norte y el sur, entre los poderosos y los que no tienen el poder, los poderosos y las víctimas, no se ve tanto a la víctima o al otro como un fin en sí mismo, sino más bien se le aborda como un objeto para conseguir una finalidad determinada. Para Dussel el poder no actúa para discutir sobre problemas éticos, sino más bien para lograr determinados fines. Esa racionalidad estratégica convierte a la persona inocente en un medio.

\section{Michael Barber:}

Por eso es importante ver que la razón práctica es diferente a la ciencia. La ciencia describe lo que es, la ética insiste en lo que debe ser. Lévinas está hablando de la misma cosa, está hablando de esta otra persona, que tiene una demanda $y$ pide una respuesta.

Lévinas estuvo en un campo de concentración. Él supo que el mundo es así como tú dices: es violento, las personas no escuchan, usan el dinero y el poder para dominar a las otras personas. Este filósofo dice que también pueden matarlos. Cuando él escribe: "los ojos de Abel miran a Caín desde la tumba" quiere decir que Caín tenía el poder de matar a Abel, pero todavía en este caso, uno puede ver que están insistiendo en que no debes hacer eso. Estoy completamente de acuerdo 
contigo. Muchas personas, en muchos países - mi país por ejemplo, que quiere resolver el problema de Irak con violencia-, no responden éticamente a la otra persona que está pidiendo una respuesta. La ética dice lo que debe ser y yo sé que algunas veces los poderes quieren justificarse, parecer como éticos. Scheller dice que la ética es un poder que no tiene poder, por ejemplo en una disputa sobre el sueldo entre los obreros y entre los dueños de una fábrica, los dos quieren parecer como justos, buenos, honrados, porque saben que van a perder legitimidad si no tienen esa ética. Es un caso de poder, pero muchas veces es un poder débil, dice Lévinas, quien describe a la ética como el poder que no tiene poder

\section{Carlos Molina:}

Asumiendo la postura de defensor de Rorty, me llama la atención que se ponga el ejemplo del campo de concentración, porque efectivamente también podríamos decir que los nazis buscaban ser vistos por sus seguidores como gente que estaba construyendo la moral, la ética, pero sin escudarse en un discurso, para el caso, de los derechos humanos, sino en el racismo presentado como idea moral. Vi hace poco un vídeo sobre el Frente Nacional español, algo así como el frente fascista, y ellos argumentan razones por las cuales se debe seguir su línea política. Esto podría dar a entender que efectivamente
Kant, Apel, Habermas, etc., tienen razón en este punto, que al final todos tratamos de argumentar nuestras posturas.

Pero Rorty podría decir: "cuando tú piensas que hay alguien que va argumentar acá para defender el racismo y tú lo interpelas y le dices que está entrando en una contradicción en el momento que te está excluyendo, al mismo tiempo que estamos discutiendo, suponiendo que no debe tener exclusión porque estamos discutiendo", Rorty dice que esto no es ninguna contradicción. Según él, no hay ninguna irracionalidad. El nazi o el que está a cargo del campo de concentración no piensan que aquí se cae en ningún tipo de contradicción irracional. Sencillamente, este sujeto está llevando sus propios planteamientos a sus últimas consecuencias.

\section{Michael Barber:}

Yo pienso que el problema con Rorty es que muchas veces él piensa que aquí hay dos grupos: aquí hay un grupo A que piensa que el racismo es malo, aquí está el otro grupo que dice que el racismo es bueno. Rorty estaría ubicado en el punto $\mathrm{C}$, encima de todo, pero sin comprometerse con nada. Por eso digo que nosotros debemos tomar una posición. Debemos escoger A o $B$, en vez de huir de la discusión. Rorty tiene la facilidad de crear un relativismo desde este nivel que está por encima de todo. Él puede ver 
que este grupo tiene una idea y este grupo otra y no pueden convencerse el uno con el otro. El relativismo es el resultado de eso.

Yo pienso que si vamos a entrar en una posición $\mathrm{A}$ o $\mathrm{B}$, y según lo que yo veo, yo pienso que el racismo es malo, y yo tengo mis razones, y en este sentido hay diferentes niveles también. Me parece que en el caso de los nazis, éstos están pensando que este judío no es un ser humano igual a mí, no tiene la misma moralidad. Lo mismo pasó en los Estados Unidos con los morenos. Las personas pensaban que no eran iguales a nosotros, que no podían leer como nosotros, pero cuando una mujer morena escribió un libro en 1700, todos los blancos tuvieron que probar que ella en realidad no escribió este libro porque era algo imposible para ellos.

Yo pienso que aquí tenemos una escisión de los hechos. Yo no veo ninguna evidencia de que un moreno no es igual a un blanco, no hay evidencias, o de que un judío sea una forma de ser humano inferior. Si es un ser igual a mí en tanto ser humano, ahora la pregunta es: ¿es esta forma de maltratar a la otra persona que es igual a ti una forma de no respetarlo como fin en sí mismo? Yo pienso que sí, es obviamente eso. Por eso el nazi que quiere argumentar conmigo - con sus razones por las cuales él cree que puede maltratar a esta otra persona-, está en una contra- dicción performativa. Es decir, que está esperando que yo lo trate a él con respeto, pero al mismo tiempo está abogando por una situación en la que él sí puede maltratar a otra persona como si esta no fuera un fin en sí mismo.

\section{Carlos Molina:}

Dussel hace otra acusación a los seguidores de Kant, y que tiene que ver con su antropología. El filósofo argentino piensa que la de Kant es una antropología dualista. ¿Cómo mira usted esto y qué piensa usted acerca de esta argumentación? También lo quiero relacionar con otro punto porque usualmente también se hace ver que muchos de estos planteamientos sobre la ética parten del supuesto que en los seres humanos, no sólo que hay dos partes, sino que hay un predominio de lo racional. Se ha escrito mucho de cómo Freud, Nietzsche y otros autores han atacado constantemente esta manera de entender al ser humano. ¿Qué piensa usted acerca de esto, es efectivamente la antropología de Kant dualista, se podría interpretar de esta manera?

\section{Michael Barber:}

Pienso que Kant psicológicamente tiene muchos desastres en su forma de pensar. Si tenemos intereses y deseos, en su opinión debemos negarlos. Por eso Dussel tiene esta objeción en contra de Kant y yo pienso que el formalismo es eso: 
es negar, es huir de los deseos, de los intereses, de mi propio bienestar; yo pienso que, al contrario, la idea de Habermas y Apel es que no debemos negar eso. Si yo tengo un interés de hacer algo, hay que preguntarse si es generalizable, universalizable. La idea de universalizar algo es solamente incluir el punto de vista de otra persona. Cuando quiero universalizar algo, voy a preguntarme si eso que quiero hacer a otra persona va a molestarla. Si no va a oprimirla, está bien. Si yo pienso que si la otra persona es un fin en sí misma, no solamente debo pensar sobre lo que es permitido hacer, también debo ayudar a esta otra persona. Kant tiene eso también, por eso no debemos excluir nuestros deseos e intereses.

Kant dice que a la hora de pensar no sólo debo tomar en cuenta mis intereses, sino que también debo tomar en cuenta lo que piensan las otras personas y mis intereses afectarán a las otras personas. En ese momento yo no debo depender de mis deseos. Esto es como decir: yo quiero hacer esto por el dinero, así que voy a reflexionar sobre la mejor manera de lograr eso. Cuando yo pienso en la mejor forma de ganar dinero, eso no es universalizable, es una forma en que mis intereses dominan mi pensamiento. Comenzamos con los máximos deseos, y vamos a reflexionar sobre eso. En la reflexión, solamente en ese momento, debemos que estos deseos influyan so- lamente si se abren a las otras personas, es decir, lo universalizable y no solamente lo que yo quiero en ese momento. Si yo decido que algo está bien y que eso que quiero es una cosa que todo el mundo puede tener, es un buen deseo, un deseo universalizable. En ese momento, yo puedo regresar y seguir satisfaciendo mis deseos en lo que quiero.

También es cierto que la ética se puede convertir en masoquismo, en represión de los deseos, como lo dicen Nietzsche y Freud. Yo planteo una forma de ética en que no debemos reprimirnos pero esto puede pasar. La represión de los deseos en nombre de la ética no es racional en realidad, es como un instrumento de los deseos: el principio de la muerte que señala Freud. Esto equivale a que yo me reprima usando la razón como un instrumento para destruirme a mí mismo. Esto es posible. En una ideología pasa la misma cosa: yo puedo usar la razón para destruir a otra persona. Esto no es la razón, es un abuso de la razón para dominar a la otra persona. Si la razón es suficientemente crítica, va a descubrir el masoquismo, el odio de uno mismo que puede esconderse detrás de la razón. Es difícil. Yo pienso que necesitamos una comunidad para hacer eso, contar con amigos que pueden ayudarnos en nuestras reflexiones éticas, que nos puedan decir: "Tú tienes una actitud negativa contra ti mismo, no debes hacer eso." También los psicólogos pueden hacer eso por nosotros. 
Quiero decir también que Freud y Nietzsche no son en realidad antimodernos, pero señalan que la racionalidad siempre debe explorar los motivos escondidos, porque es una cuestión de honradez. Nietzsche dijo que la cristiandad iba a matarse porque su primer mandamiento era la prohibición de mentir. Nietzsche está tratando de no mentir, de ser racional, de descubrir lo que en el fondo son mis motivos. Esa es una obra de la racionalidad.

\section{Carlos Molina:}

Yo pienso que si lo planteamos de otra forma, es como si dijéramos que esta racionalidad tiene problemas, puede incluso ser manipulada, pero incluso cuando estamos usando la razón para perseguir nuestros intereses sin importarnos los demás, o cuando esta razón es un mecanismo para la represión, incluso al sentarse a reflexionar sobre esta situación que estoy viviendo, yo reconozco como esta otra concepción de la razón que es la correcta. Pero, ¿qué pasa si se plantea una situación distinta? Voy a referirme aquí a lo que plantea Bernard WiIliams en su libro Moral luck, que sería algo así como Suerte moral. Pareciera que los problemas sobre los que vamos a discutir son como los mismos o muy similares, pero en la vida práctica hay decisiones que toman ciertas personas. Por ejemplo, un muchacho joven que vive en un barrio popular en El Salvador, en Soyapango digamos o en Ilopan- go, un miembro de una pandilla por ejemplo, que a los 18 o 20 años ha tomado una serie de decisiones que yo o los que estamos acá nunca hemos tomado en nuestras vidas: por ejemplo la decisión entre matar o no. Este muchacho a lo mejor ha tomado muchas veces esta decisión. Podríamos decir que la moral referida a estas personas es lo mismo que estamos discutiendo nosotros ahora, que somos individuos que toman otro tipo de decisiones. Por ejemplo, decisiones que yo he tomado en mi vida sobre si me he de casar, si he de estudiar una carrera o no. $\mathrm{O}$ decisiones de un funcionario que tienen que ver con las políticas públicas, la decisión sobre una política pública de salud o de educación, por ejemplo, que a lo mejor a largo plazo pueden generar muertes, pero nunca son decisiones entre si he de matar o no. Bernard Williams dice que aquí hay un elemento de irracionalidad que se cuela. No sé si lo he interpretado mal. Yo creo que no. Williams pregunta: ¿qué es lo que se ha metido acá? Se ha metido la suerte. Es decir, los aquí presentes tenemos la suerte de no haber nacido en ese lugar y en esas condiciones y de no ser hijos de estas personas y de no tener esos vecinos, porque nunca nos hemos vistos enfrentados a tomar estas decisiones. Pero esto no es una condición que compartimos todos los humanos. Algunos tenemos la suerte de nacer en esta situación y otros no. Por lo tanto, ahí hay un elemento de irracionalidad en la base. Bernard 
Williams diría entonces que no se puede hablar de una especie de homogeneidad. No se pueden tomar ciertas decisiones si no estamos anclados en una situación concreta. Es esa situación concreta la que nos enfrenta a esas decisiones.

Desplazando un poco el problema, no sólo de si tenemos estructuras de razonamiento muy similares, o universales, sino que es la suerte la que nos pone en ciertas situaciones y que, por lo tanto, pareciera que eso exige morales diferentes, ¿esto nos exige pensar en estructuras de decisión distintas, o incluso en estructuras de valores diferentes?

\section{Michael Barber:}

Esto tiene que ver con las razones externas. Bernard Williams habla de las razones internas del sujeto. Ese autor está en contra de las razones externas, es decir, de algo que es independiente de una persona, por ejemplo, cómo creció esta persona. Yo pienso que en realidad esto tiene el problema de llegar a la conclusión de que si yo tengo esta ética interna que he recibido desde mi juventud no hay ninguna forma de criticarla, porque tú no podrías decir que mis decisiones no son buenas, nadie podría decir eso. Me parece que se llega a un punto de relativismo otra vez. si la forma en que te criaste es diferente a la mía, entonces no puedo criticar lo que piensas y que no podríamos decidir quién tiene la razón en esta situación.

Yo pienso que hay una posibilidad de hablar desde una razón que puede criticar esta forma de pensar. Otra vez voy a usar a mi amigo Apel y a Habermas. Creo que si tú eres una persona que pretende decir que no se le pueden juzgar sus decisiones, al mismo tiempo estás suponiendo que yo voy a escucharte, que yo voy a responderte a lo que dices, entonces tenemos aquí la racionalidad.

Pienso, por ejemplo, en los diálogos entre las religiones, entre los musulmanes y los cristianos. Son personas que crecieron en diferentes lugares, con diferentes valores y todo esto. Siempre hay personas que quieren defender los valores musulmanes, es decir, están ofreciendo una justificación. También los cristianos hacen lo mismo: están esperando que la otra persona los escuche, que responda, pero no con violencia, no con coerción, pero que va a escuchar o a criticarme, o que yo puedo tener una respuesta, pero en todo caso, respetándonos los unos con los otros como fines en nosotros mismos.

Muchas veces esos jóvenes que han hecho cosas como jóvenes pueden mirar hacia atrás años después y pueden decir: yo he hecho cosas malas en mi vida. Pienso que en ese momento tienen más racionalidad, porque pueden ver que no se han 
tratado bien a sí mismos, o que no han tratado bien a otras personas. De todos modos esta situación es una tragedia de la suerte moral: hay personas que no han crecido en un ambiente bueno, nosotros reconocemos eso.

Desde mi propio punto de vista esto me causa más simpatía por ellos. En vez de decir que ellos tienen diferente razón que yo, yo voy a decir que estos pobrecitos sufrieron tanto que su razón fue desfigurada un poco por su ambiente sociopolítico y psicológico. Por eso yo voy a sentir más responsabilidad en cambiar esta situación sociológica, sicológica, política. Si yo pienso que esta persona que roba y que mata tiene diferentes creencias por la forma en que creció, ¿qué razón tengo yo para cambiar su situación? Esta es una forma conservadora de mantener la situación como es. Por eso la razón es crítica, es una forma de desafiar las situaciones. Kant siempre pensó que la ciencia tiene que conformarse con el mundo, pero la ética debe decir que el mundo tiene que cambiar. Esto para mí es una cosa interesante. 